\title{
Impact of carbamylation and glycation of collagen type I on migration of HT1080 human fibrosarcoma cells
}

\author{
GEORGES SAID ${ }^{1}$, MARIE GUILBERT ${ }^{1}$, EMILIE MILLEROT-SERRUROT ${ }^{1}$, LAURENCE VAN GULICK ${ }^{1}$, \\ CHRISTINE TERRYN $^{2}$, ROSELYNE GARNOTEL ${ }^{1}$ and PIERRE JEANNESSON ${ }^{1}$ \\ ${ }^{1}$ FRE CNRS/URCA no. 3481, Faculty of Pharmacy; ${ }^{2}$ Cellular and Tissular Imaging Platform, \\ 51 Rue Cognacq-Jay, 51096 Reims Cedex, France
}

Received November 24, 2011; Accepted January 17, 2012

DOI: 10.3892/ijo.2012.1393

\begin{abstract}
Collagen type I is an abundant component of the extracellular matrix and due to its longevity, constitutes a prominent target of non-enzymatic post-translational in vivo modifications such as carbamylation and glycation. These protein modifications involved in aging, renal diseases and diabetes, are linked to elevated cancer risk. In this in vitro study, we investigated the impact of carbamylated and glycated collagen type I on the migratory behavior of the highly invasive HT1080 human fibrosarcoma cells. The proliferation of HT1080 on modified collagens did not differ from that on native form. The glycated collagen delayed the cell adhesion time whereas the carbamylated one had no effect. The migration ability of HT1080 was studied by quantifying single cell speed using videomicroscopy. Glycation strongly inhibited mean cell speed by $47 \%$ whereas carbamylation moderately affected it by $12 \%$. In addition, the influence of these collagen modifications on actin and vinculin organization was studied. On the glycated collagen, $63 \%$ of cells revealed a dramatic loss of actin stress fibers vs. $28 \%$ on the carbamylated one. In these cells, disorganized F-actin was accompanied with a disturbance of vinculin and both proteins were localized at the rim of the cells. Concerning the focal adhesion kinase (FAK) expression, glycated collagen only induced a significant inhibition. Whereas, both collagen modifications provoked a differential inhibition of FAK phosphorylation state by $25 \%$ for carbamylation and $60 \%$ for glycation. In conclusion, our
\end{abstract}

Correspondence to: Professor Pierre Jeannesson, FRE CNRS/ URCA no. 3481, Faculty of Pharmacy, 51 Rue Cognacq-Jay, 51096 Reims Cedex, France

E-mail: pierre.jeannesson@univ-reims.fr

Abbreviations: ESRD, end-stage renal disease; RCC, renal cell carcinoma; AGE, advanced glycation end-products; FAK, focal adhesion kinase; HPLC, high-performance liquid chromatography; ECM, extracellular matrix; KCNO, potassium cyanate; MEM, minimum essential medium; SDS-PAGE, sodium dodecyl sulfatepolyacrylamide gel electrophoresis

Key words: carbamylation, cell migration, collagen type I, cytoskeleton, glycation, HT1080 cells data suggest that, in vivo, collagen glycation and carbamylation may affect tumor cell metastasis. This suggestion is supported by clinical studies reporting less aggressive tumors in diabetic or uremic patients. Consequently, the impact of such posttranslational modifications has to be taken into account in order to better understand the link between aging, diabetes or uremia and cancer progression.

\section{Introduction}

Carbamylation and glycation are well-known post-translational modifications which occur throughout the lifespan of proteins in vivo. They are due to the non-enzymatic binding of various low molecular weight molecules to the free amino groups where lysine is reported as being the commonly involved amino acid (1). Carbamylation results from the binding of isocyanic acid, spontaneously deriving from high concentration of urea and leading to the formation of homocitrulline from lysine residues (2). Glycation is initiated by spontaneous binding of carbonyl groups of reducing sugars to form Schiff bases and then Amadori products. These products undergo further complex reactions that induce the formation of stable adducts and cross-links of proteins currently called advanced glycation endproducts (AGE) $(3,4)$. These post-translational modifications of proteins have been described in pathological as well in physiological circumstances and in both cases they are suggested to be associated to cancer development. High blood concentrations of urea leading to the carbamylation process were detected in patients with end-stage renal disease (ESRD) (2). Those patients on dialysis show a higher prevalence for renal cell carcinoma (RCC) than age-matched healthy controls (5). In a similar way, AGE concentration is increased in tissues of elderly people or in diabetic patients (6); two situations highly correlated to cancer. The incidence of cancers rises markedly in patients of advanced age (7) where tumors are less metastatic than those in younger patients (8). In addition, recent studies suggested that diabetes is associated with an increased risk of cancers of the liver, pancreas, colon, kidney and breast (9).

Collagen type I can be considered as a prominent target of carbamylation and glycation, due to its particular longevity with an estimated half-life of 15 years in humans (10). These post-translational modifications of collagen type I are irreversible and cumulative $(11,12)$. Interestingly, collagen type I is a 
main component of connective tissues and plays a key role in the adhesion/migration process of tumor cells preparing at this stage the formation of metastases. Consequently, further investigations on the effects of post-translational modifications on the migration parameters and machinery of single cells are needed. They will contribute to a better understanding of the relationship between physiopathological modifications of collagen and the tumor cell behavior.

In the present in vitro study, we investigated the influence of carbamylated and glycated coated-collagen on the migratory behavior of the human HT1080 fibrosarcoma cell line. The proliferative capacity was first determined, and then at the single cell level, the migratory parameters were defined by time-lapse videomicroscopy, as well as the actin and vinculin organization and, the expression and the activation state of focal adhesion kinase (FAK) that is involved in the formation of focal adhesion complexes and cell motility.

\section{Materials and methods}

Cell line. The human fibrosarcoma cell line HT1080 (CCL-121) was purchased from the American Type Culture Collection (ATCC, Rockville, USA) and cultured in MEM with Earle salts and Glutamax I (Invitrogen, Cergy-Pontoise, France) supplemented with $10 \%$ fetal calf serum (Invitrogen) and $1 \%$ penicillin-streptomycin (Invitrogen). Cultures were maintained at $37^{\circ} \mathrm{C}$ in a humidified atmosphere containing $5 \% \mathrm{CO}_{2}$ $(\mathrm{v} / \mathrm{v})$. Cells were routinely passaged at preconfluency using $0.05 \%$ trypsin, $0.53 \mathrm{mM}$ EDTA (Invitrogen) and screened for the presence of mycoplasma using PCR methods.

Preparation of carbamylated or glycated collagen type I. Fibrillar, non-pepsinized collagen type I was extracted from rat tail tendons and prepared as already described (13). Under sterile conditions, the lyophilized collagen $(1 \mathrm{mg} / \mathrm{ml})$ was incubated, at $37^{\circ} \mathrm{C}$ for $24 \mathrm{~h}$, with different concentrations of KCNO (Sigma) in $0.15 \mathrm{M}$ phosphate buffer $\mathrm{pH} 7.4$ to obtain carbamylated collagen. Glycated collagen was obtained by incubating at $37^{\circ} \mathrm{C}$ for 5 days the lyophilized collagen $(1 \mathrm{mg} / \mathrm{ml})$ with different concentrations of ribose (Sigma, L'isle d'Abeau Chesnes, France) in $0.15 \mathrm{M}$ phosphate buffer $\mathrm{pH}$ 7.4. Both types of modified collagens were extensively dialysed against distilled water for 3 days, $0.018 \mathrm{M}$ acetic acid for 2 days and then lyophilized.

Electrophoretic properties of carbamylated collagen were estimated by $5 \%$ sodium dodecyl sulfate-polyacrylamide gel electrophoresis (SDS-PAGE), under denaturing conditions ( 2 min for $90^{\circ} \mathrm{C}$ ). Gels were stained with Coomassie Brillant Blue R250. To quantify the number of homocitrulline residues generated by carbamylation, $0.5 \mathrm{mg}$ of collagen $(2 \mathrm{mg} / \mathrm{ml})$ were hydrolyzed in $12 \mathrm{M} \mathrm{HCl}$ for $18 \mathrm{~h}$ at $110^{\circ} \mathrm{C}$. Analysis of amino acid composition was performed by HPLC (Hitachi L-8800) with cations exchange column. Collagen glycation was quantified by measuring the collagen autofluorescence under spectrofluorimetry at $\lambda_{\text {exc }}=380 \mathrm{~nm}$ and $\lambda_{\text {emi }}=440 \mathrm{~nm}$ (Shimadzu Rf-500).

Cell proliferation, adhesion and migration. The effects of the carbamylated or glycated collagen type I on HT1080 cell proliferation were studied using 24-well plates. Each well was coated by adding $250 \mu \mathrm{l}$ of native or modified collagens solubilized in $0.018 \mathrm{M}$ acetic acid at a concentration of $35 \mu \mathrm{g} / \mathrm{ml}$. Then, coated substrates were dried overnight at room temperature under sterile conditions and rinsed once in PBS (Invitrogen) before cell plating. HT1080 cells were seeded on the coated surfaces at a concentration of $25 \times 10^{3}$ cells/well $(1 \mathrm{ml} /$ well $)$. Cell viability and cell number were determined by phase contrast microscopy after 24, 48 and $72 \mathrm{~h}$ of incubation.

The cell adhesion assay was performed in 12-well plates. Each well was coated with $500 \mu \mathrm{l}$ of the different collagens at $35 \mu \mathrm{g} / \mathrm{ml}$. A total of $1 \mathrm{ml}$ of cells $\left(60 \times 10^{3}\right)$ was seeded in each well and incubated for $0.5-4 \mathrm{~h}$ at $37^{\circ} \mathrm{C}$. After the incubation times, wells were gently washed with PBS to remove unattached cells. Then, the remaining bound cells were detached with trypsinEDTA and counted. Percentage of adhesion was calculated by considering the cells in the initial suspension as $100 \%$.

For the cell migration assay, $2 \mathrm{ml}$ of cells/well (10x10 3 cells) were seeded in 12-well plates coated in the same conditions as above. Cell motility was analyzed by time-lapse videomicroscopy using an inverted microscope Axiovert $200 \mathrm{M}$ (Zeiss, Le Pecq, France) equipped with a small transparent environmental chamber Climabox (Zeiss), at $37^{\circ} \mathrm{C}$ in an humidified atmosphere containing $5 \%(\mathrm{v} / \mathrm{v}) \mathrm{CO}_{2}$. The microscope was driven by the Metamorph software (Roper Scientific, Evry, France) and images were recorded with a charge-coupled device camera CoolsnapHQ (Roper Scientific). Cell speed was quantified $(\mu \mathrm{m} / \mathrm{h})$ for each individual non-mitotic cell using an interactive tracking method as previously described (14).

Actin and vinculin staining. Cells were seeded in 35-mm glassbased dishes (Dutscher, Brumath, France) coated with $2 \mathrm{ml}$ of the different collagens at $35 \mu \mathrm{g} / \mathrm{ml}$. After $24 \mathrm{~h}$ of incubation, cells were washed with PBS and fixed using $4 \%$ paraformaldehyde in PBS for $10 \mathrm{~min}$ at room temperature. After 3 further washes and permeabilization with $0.5 \%$ Triton $\mathrm{X}-100$ in PBS for 5 min, cells were blocked with PBS containing 3\% bovine serum albumin for $30 \mathrm{~min}$. Then, a primary monoclonal antibody specific for vinculin (Clone hVIN-1, Sigma) was applied for $60 \mathrm{~min}$ at room temperature and staining was detected with Alexa Fluor 568 conjugated secondary antibody (Invitrogen). F-actin was detected using Alexa Fluor 488 Phalloidin (Invitrogen). After cell washing, fluorescence images captured with the microscope Axiovert $200 \mathrm{M}$, were treated with MetaMorph ${ }^{\circledR}$ software using a deconvolution algorithm to eliminate fluorescent backgrounds. The number of cells showing organized actin stress fibers was determined by direct fluorescent counting and cell surfaces (pixels) were quantified using Image ${ }^{\circledR}$ software.

FAK activation assay. Cells were lyzed with extraction buffer [0.01 M Tris-HCl, 0.15 M NaCl, 0.005 M EDTA, 1\% (v/v) SDS $10 \%, 1 \%$ (v/v) glycerol, $\mathrm{pH} 7.4]$. Cell lysates were clarified by centrifugation at $450 \mathrm{xg}$ at $4^{\circ} \mathrm{C}$ for $4 \mathrm{~min}$. Briefly, proteins were separated by $9 \%$ SDS-PAGE gels and transferred to a PVDF membrane. Then, membranes were blocked with Trisbuffered saline (TBS) (0.02 M Tris- $\mathrm{HCl}, 0.137 \mathrm{M} \mathrm{NaCl}, \mathrm{pH} 7.4)$ containing $0.1 \%$ Tween (TBS-T) and 5\% non-fat dry milk at room temperature during $2 \mathrm{~h}$ and incubated overnight at $4{ }^{\circ} \mathrm{C}$ with either mouse monoclonal antibodies raised against total FAK (1:5000, Millipore, Saint-Quentin en Yvelines, France) or (Y397) phosphorylated-FAK (1:1000, Millipore). Membranes 
A

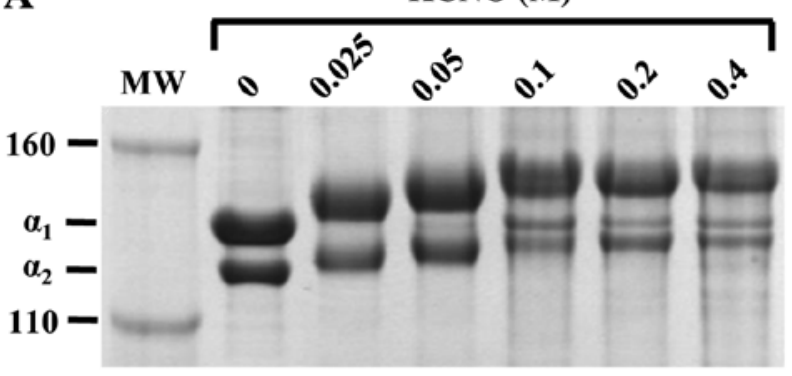

B

\begin{tabular}{lcc}
\multicolumn{3}{c}{ Homocitrulline content in carbamylated collagen } \\
\hline & \multicolumn{2}{c}{ Number of residues per 1000 amino acids } \\
\cline { 2 - 3 } KCNO & Lysine & Homocitrulline \\
\hline Control & 28 & n.d. \\
$0.025 \mathrm{M}$ & 16 & 12 \\
$0.05 \mathrm{M}$ & 13 & 15 \\
$0.1 \mathrm{M}$ & 8 & 20 \\
$0.2 \mathrm{M}$ & 8 & 20 \\
$0.4 \mathrm{M}$ & 8 & 20 \\
\hline n.d.: not detectable &
\end{tabular}

Figure 1. Biochemical characteristics of carbamylated collagen. (A) SDSPAGE of carbamylated collagen, $25 \mu \mathrm{g}$ of either native or KCNO-treated collagens for $24 \mathrm{~h}$ at $37^{\circ} \mathrm{C}$ were analyzed on $5 \%$ polyacrylamide gels under denaturing conditions. MW, standard high molecular weight markers. (B) Analysis of homocitrulline content in the different carbamylated collagens mentioned above. The number of homocitrulline and lysine residues was determined by HPLC after acid hydrolysis. Data shown in (A) and (B) are representative of three independent experiments.

were washed with TBS-T and incubated with peroxidaseconjugated anti-mouse IgG (1:20000, Millipore) at room temperature for $1 \mathrm{~h}$. Chemiluminescent detection was realized by using an $\mathrm{ECL}^{+} \mathrm{Kit}$ (GE Healthcare, Orsay, France).

Statistical analysis. Data are presented as mean \pm SEM except for migration speed which displayed as box-blot ranging from the 25th-75th percentile including the median and whiskers from the 5th-95th percentile. The values were analyzed with Kruskall-Wallis followed by Mann-Whitney test. Statistical significance was set at $\mathrm{p}<0.05$.

\section{Results}

Characterization and identification of carbamylated and glycated collagen type I. Carbamylation was performed by incubating collagen type I, with increasing potassium cyanate (KCNO) concentrations ranging from 0.025 to $0.4 \mathrm{M}$, at $37^{\circ} \mathrm{C}$ for $24 \mathrm{~h}$. The level of carbamylation was assessed by electrophoresis and high performance liquid chromatography (HPLC) that permitted to estimate homocitrulline residue content. As shown in Fig. 1A, native collagen exhibited two characteristic bands corresponding to $\alpha_{1}$ and $\alpha_{2}$ chains. With carbamylated

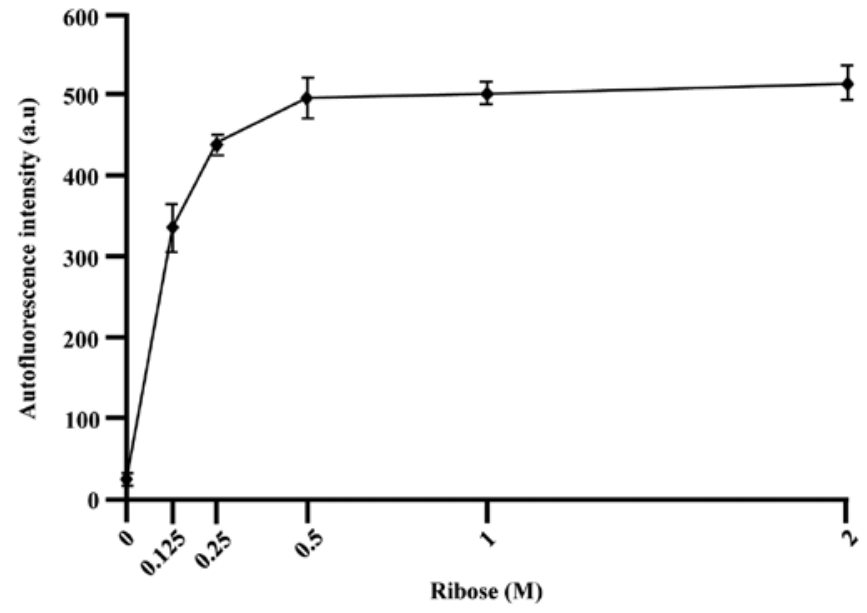

Figure 2. AGE formation on glycated collagen. Detection of autofluorescence intensity of glycated collagens obtained after a 5-day incubation at $37^{\circ} \mathrm{C}$ with increased ribose concentrations $(0.125,0.25,0.5,1$ and $2 \mathrm{M})$. The graph shows the mean value of three independent experiments.

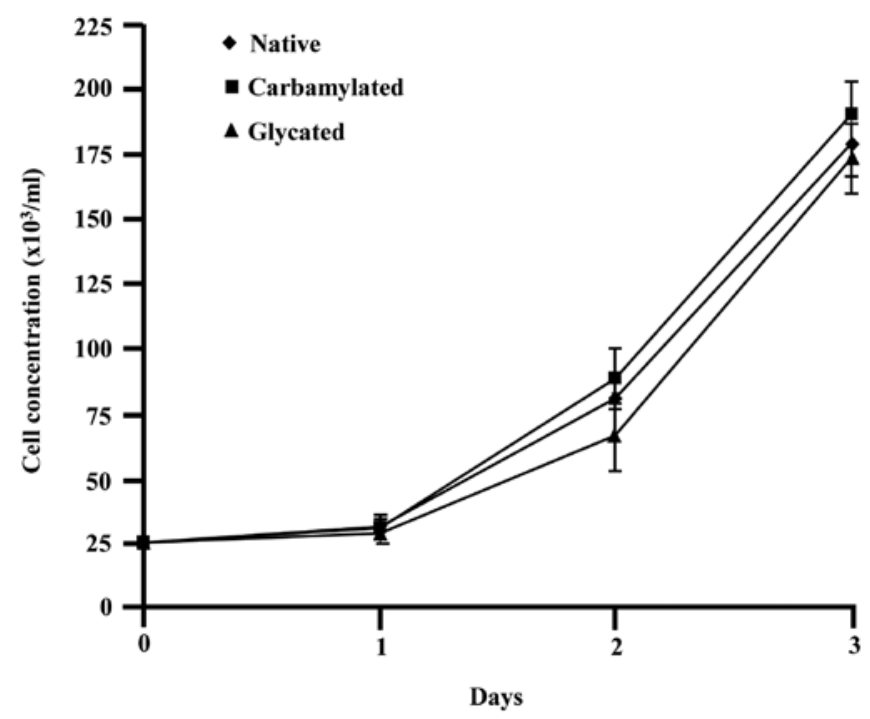

Figure 3. Proliferation of HT1080 cells cultured on native, carbamylated or glycated collagens. Cells were seeded on collagen-coated 24 -well plates at $25 \times 10^{3}$ cells/well. Cell numbers were evaluated by phase contrast microscopy. The graphs show the mean values of three independent experiments.

collagen, the more the cyanate concentration increased, the slower the $\alpha$ chains migrated to reach a plateau at $0.1 \mathrm{M}$. In addition, HPLC amino acid analysis revealed that native collagen did not contain homocitrulline residues, contrarily to carbamylated collagens. Indeed, these residue indicators of lysine carbamylation gradually increased between $0.025 \mathrm{M}$ and $0.1 \mathrm{M} \mathrm{KCNO} \mathrm{(12} \mathrm{and} 20$ homocitrulline residues per 1000 amino acids, respectively) to reach a plateau (Fig. 1B).

Glycation was performed with increasing ribose concentrations ranging from 0.125 to $2 \mathrm{M}$ at $37^{\circ} \mathrm{C}$ for 5 days. Using spectrofluorimetry, glycation was quantified by detecting fluorescing AGE. Fig. 2 shows that glycated collagen autofluorescence progressively increased as of $0.125 \mathrm{M}$ ribose [335 arbitrary units (a.u.) vs. 26 for native form] and reached a plateau for $0.5 \mathrm{M}$ ribose (495 a.u.). In all further experiments, 


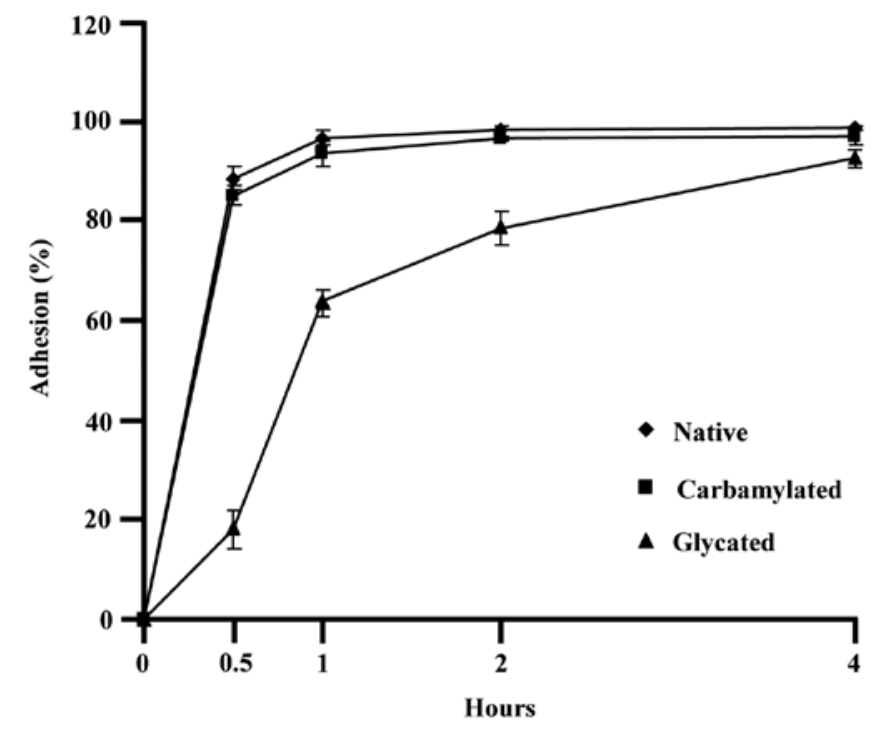

Figure 4. Effect of carbamylated or glycated collagen on HT1080 cell adhesion. The adhesion assay was performed on collagen-coated 12 -well plates at $60 \times 10^{3}$ cells/well. Adherent cells were counted as described in experimental procedures. Data shown are the mean of three independent experiments.

the respective impacts of carbamylation and glycation on HT1080 cell adhesion and migration were studied for collagens exhibiting the highest amount of homocitrulline residues (0.1 M KCNO) or AGE production (0.5 $\mathrm{M}$ ribose).

Carbamylation and glycation did not affect HT1080 cell proliferation. Cells were seeded on surfaces coated with native, carbamylated or glycated collagen and cell proliferation was monitored during the first 3 days of culture (Fig. 3). After a one day of latency phase, similar cell proliferation profiles were obtained with the different substrata at days 2 and 3. These results indicate that carbamylation and glycation did not influence the proliferation of HT1080 cells compared to native collagen.

Differential impact of carbamylation and glycation on HT1080 cell adhesion. As shown in Fig. 4, we examined whether carbamylation and glycation affected the cell adhesion process, which is a basic prerequisite for efficient cell migration. After only $30 \mathrm{~min}$ of incubation at $37^{\circ} \mathrm{C}, 90 \%$ of cells adhered on native collagen. Similar results were obtained with carbamylated collagen. By contrast, cell adhesion on glycated collagen was markedly delayed since only $20 \%$ of cells had adhered at that time point. Similarly, after $1 \mathrm{~h}$ most of the HT1080 cells adhered on native collagen vs. $65 \%$ on the glycated one. It is only after $4 \mathrm{~h}$ of incubation that the percentage of cells adherent to glycated collagen were identical to that found with native and carbamylated collagens.

Differential inhibition of carbamylation and glycation on HT1080 cell migration. We next evaluated whether the post-translational modifications of collagen type I modulated HT1080 cell migration (Fig. 5). The migration speed of individual cells cultured on surfaces coated with the different collagens was thus quantified using time-lapse videomicroscopy. As early as day 1 of culture, glycation induced a marked anti-migratory effect by inhibiting cell speed by $47 \%$. Indeed, on glycated collagen, cells exhibited a median speed

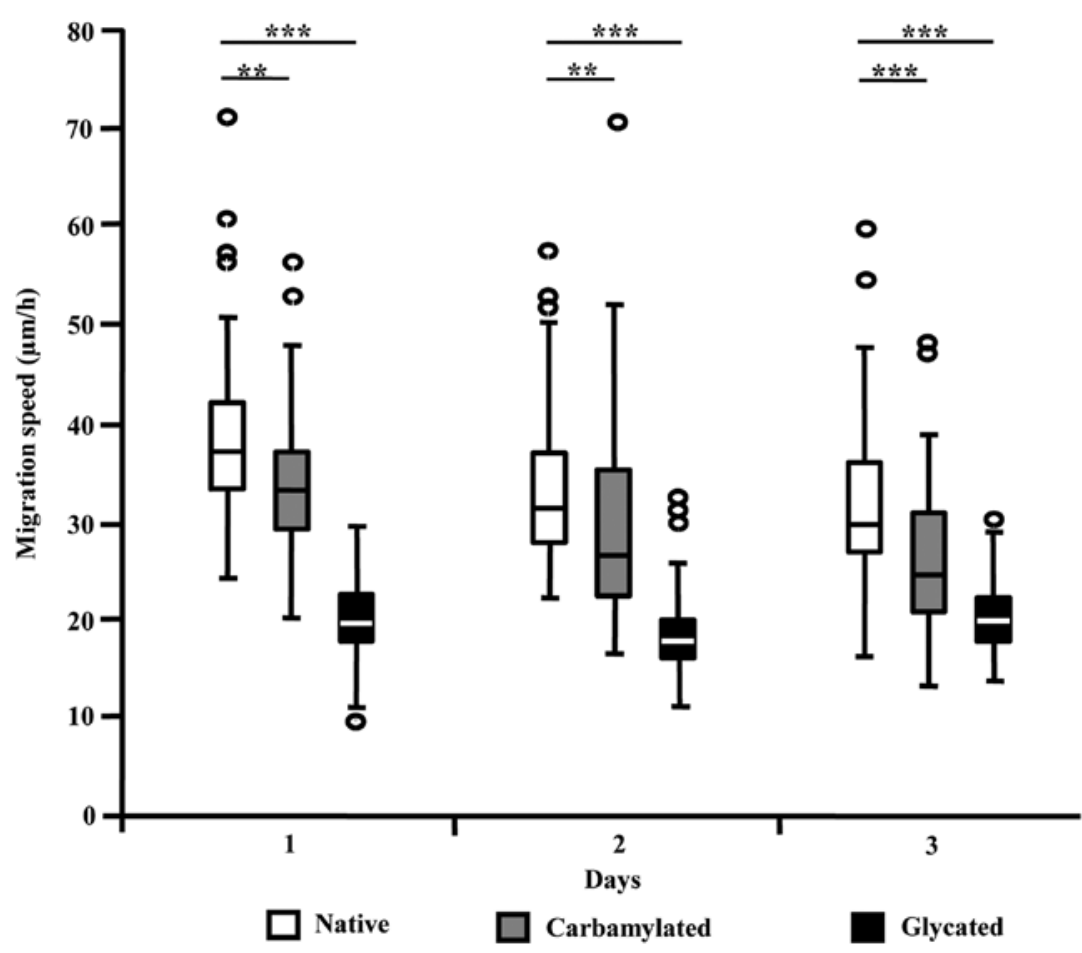

Figure 5. Effect of carbamylated or glycated collagen on HT1080 cell migration. Cells were cultured on collagen-coated 12-well plates at 10x10 3 cells/well. Cells were tracked by time-lapse videomicroscopy during the last $6 \mathrm{~h}$ of each day. The migration speed was displayed as box plot (bottom of box, 25 th percentile; and top of box, 75 th percentile) and the middle line indicates the median ( 80 cells/condition). ${ }^{* *}$ p $<0.01,{ }^{* * * *}$ p $<0.001$ significant differences between native and modified collagens. 
A
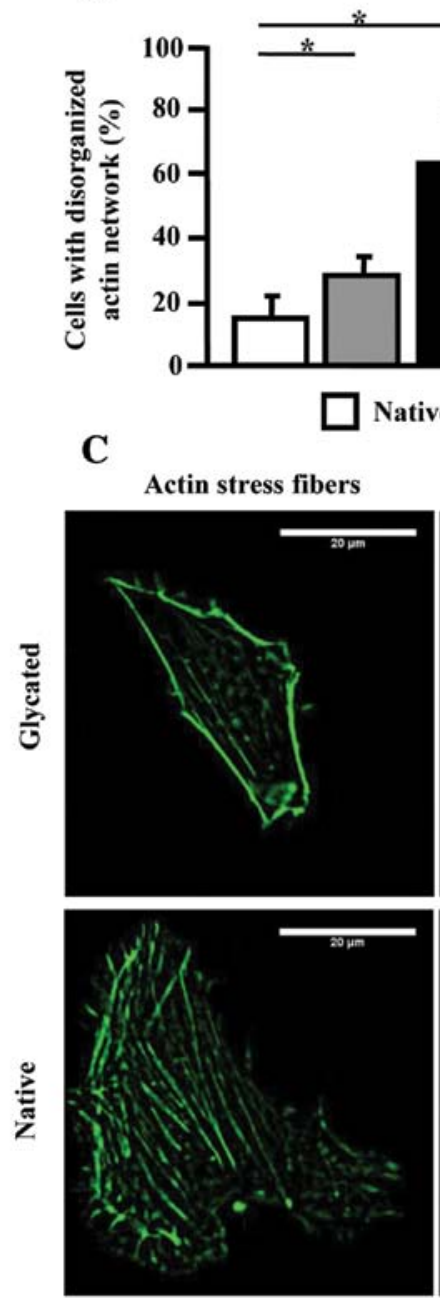

B

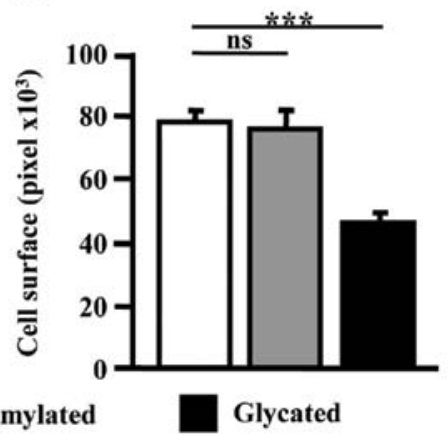

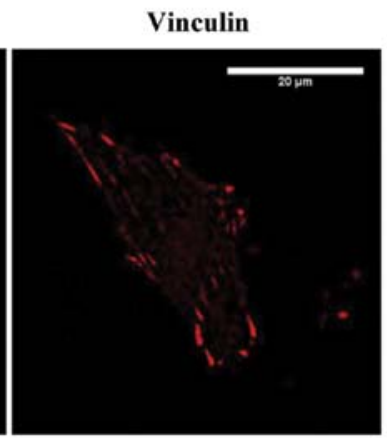
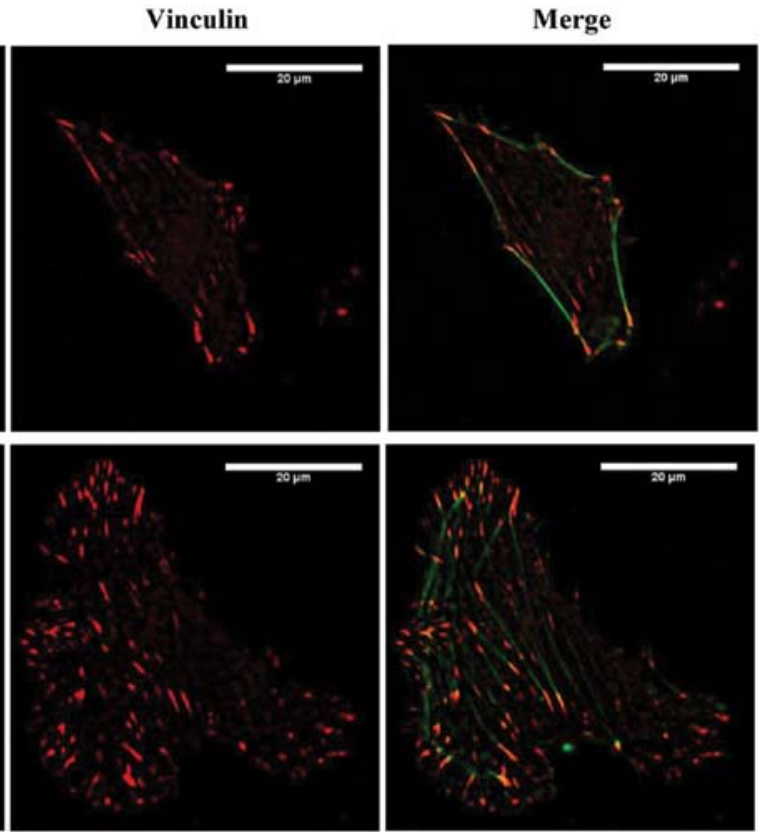

Figure 6. Impact of modified collagens on HT1080 cell morphology and cytoskeletal organization. Cells were plated on coated surfaces 24 h at $37^{\circ} \mathrm{C}$. (A) Cells were stained for F-actin as described in experimental procedures and statistically analyzed for actin disorganization. (B) Cell surface areas were quantified using Image $J^{\circledR}$. Values are the means of three independent experiments, ${ }^{*} \mathrm{p}<0.05,{ }^{* * *} \mathrm{p}<0.001$. (C) Representative fluorescence images of F-actin (green), vinculin (red), and merge in cells cultured on native and glycated collagens. Scale bars, $20 \mu \mathrm{m}$.

of $20.2 \mu \mathrm{m} / \mathrm{h}$ compared to $38.8 \mu \mathrm{m} / \mathrm{h}$ for those cultured on native collagen. In contrast, carbamylation induced a moderate but significant $12 \%$ inhibition of cell speed. For both collagen modifications, identical cell speed inhibitions were obtained at days 2 and 3 of culture.

Impact of carbamylation and glycation on cell morphology and cytoskeletal organization. The observed decrease of cell motility in presence of modified collagens was accompanied by cytoskeletal and morphological changes specially marked with glycated collagen. As shown in Fig. 6A, 63\% of cells migrating on glycated collagen exhibited a disorganized actin network vs. $28 \%$ with carbamylated form. It should be noted that with native collagen, $18 \%$ of the cells presented disorganized actin which could correspond to cells undergoing mitosis. The area of individual migrating cells was also affected on glycated collagen (Fig. 6B), as it was significantly decreased by about $41 \%$ compared to native and carbamylated collagens. Cell morphology changes and disorganization of both actin and vinculin that are considered as key proteins involved in cell migration are illustrated in Fig. 6C for glycated collagen.
This cell presented an elongated shape, a loss of actin stress fibers and a disorganization of vinculin. Actin was principally localized at the rim of the cell and in a very small network throughout the cytoplasm. Vinculin patches were essentially localized at the cell periphery and less detected at the cytoplasmic level. By contrast, a representative cell cultured on native collagen exhibited classical tear-drop morphology with a broad lamellipodium and a narrow tail. In addition, this cell displayed, throughout the cell body, many actin stress fibers at the end of which vinculin patches were localized. Concerning the carbamylated collagen, we observed that the majority of cells presented the same phenotypic aspect as the native form.

Effect of carbamylation and glycation on FAK expression and activation. Due to the role of the non-receptor protein tyrosine kinase FAK in cell motility regulation, both its expression and activation state were examined by western blot analysis. As shown in Fig. 7, carbamylation did not affect FAK expression and only induced a moderate decrease of FAK activation by $15 \%$. By contrast, glycated collagen affected both total expres- 

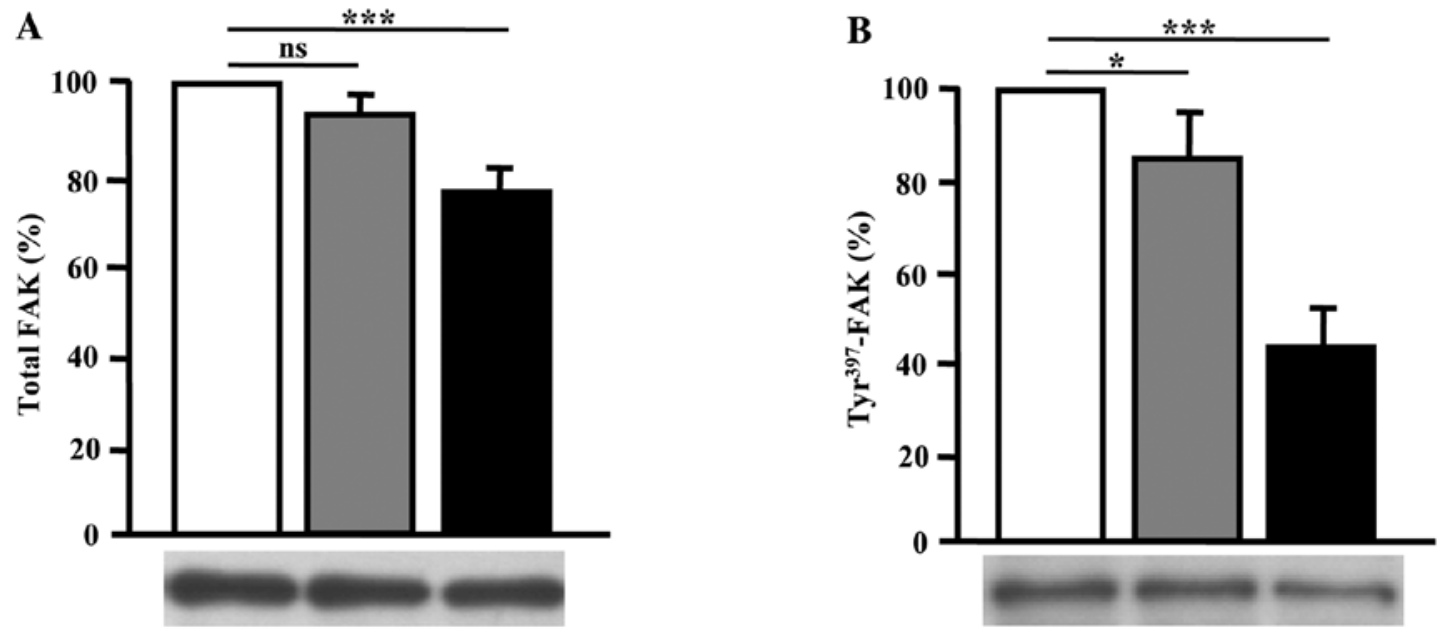

$\square$ Native $\square$ Carbamylated $\square$ Glycated

Figure 7. Effect of modified collagens on FAK expression and activation state in HT1080 cells. Cells were cultured for $24 \mathrm{~h}$ on wells coated with native or modified collagens. (A) Total-FAK and (B) phosphorylated Tyr ${ }^{397}$-FAK. The graphs show the mean values of three independent experiments. Representative immunoblots are presented below the graphs. ${ }^{*} \mathrm{p}<0.05,{ }^{* * *} \mathrm{p}<0.001$; ns, not significant.

\begin{tabular}{|c|c|c|c|c|c|c|c|}
\hline & & & & & & & \\
\hline 11 & CDGVLCKEDL & DCPNPQKREG & ECCPFCPEEY & & EGPKGDPGPQ & GPRGPVGPPG & 120 \\
\hline 21 & QDGIPGQPGL & PGPPGPPGPP & GPPGLGGNFA & SQMSYGYDEK & SAGVSVPGPM & GPSGPRGLPG & 180 \\
\hline & PPGAPGPQGF & QGPPGEPGEP & GASGPMGPRG & PPGPPGKNGD & & & \\
\hline 1 & ARGLPGTAGL & PGMKGHRGFS & DGAKGDTG & PAGPKGEPGS & & & \\
\hline 1 & RPGPPGSAGA & RGNDGAVGAA & GPPGPTGPTG & PPGFPGAAGA & KGEAGPQGAR & GSEGPQGVRG & 60 \\
\hline & EPGPPGPAGA & AGPAGNPGAD & & APGIAGAPGF & & & \\
\hline & NSGEPGAPGN & AKGEP & & KRGA & & & \\
\hline 31 & SRGFPGADGV & PAGER & GSPGPA & RPGE & GLT & GSPG & 40 \\
\hline & KTGPPGPAGQ & AGPP & MG & GE & & & \\
\hline & KDGEA & PAGER & PG & & GEQ & GVPG & \\
\hline 1 & PSG & PGERGVQGPP & GPAC & KGD & & MPG & 720 \\
\hline 1 & ERGA & KGDRGDAGPK & DG & $G P$ & & & 80 \\
\hline 81 & APGD & RGE PGPPGPA & GFAG & EPGD & $G P P$ & GPAG & 840 \\
\hline & PIGI & & & & & & \\
\hline & ETGPAGRPGE & GPPGPPGPA & DG & PGP & & ERG & 60 \\
\hline & FPGLPGPSGE & PGKQGPSGAS & GERGPP & PPGE & SGREGSPGAE & GSPGR & 1020 \\
\hline & AKGDRGETGP & AGPPGAPGAP & & & & & \\
\hline & PRGDKGETGE & KGHR & PG & QGP & & PPG & \\
\hline & KDGLNGLPGP & IGPPGPRGRT & GDSGPAGPPG & PPGPPGPPGP & PSGGYDFSFL & PQPPQEKSQD & 200 \\
\hline & GGRYYRADDA & VVRDRDLEV & & & & & \\
\hline & GEYWIDPNQG & NLDA & NMETC & & & SMT & \\
\hline & DGFQFEYGSE & GSDPADVAIQ & LTFLRLMS & ASQNITYHCK & NSVAYMDQQT & GNLKKSLLLQ & 38 \\
\hline & & GNSRFTYSTL & & VGKTVIEYKT & TKTSRLPIID & VAPLDIGAPD & \\
\hline & & & & & & & \\
\hline
\end{tabular}

Figure 8. Amino acid sequence of the rat collagen type I $\alpha_{1}$ chain (P02454, http://www.uniprot.org/uniprot/P02454). The preferential glycation motifs PKG and AKG are indicated in yellow and the cell binding RGD motifs are in red.

sion and enzyme activity. Indeed, glycation inhibited FAK expression by $25 \%$ and phosphorylation state by $60 \%$.

\section{Discussion}

In this in vitro study, we provide evidence that both glycation and to a lesser extent carbamylation of collagen type I inhibit invasive cell migration of human HT1080 fibrosarcoma cells without affecting their proliferation. Collagen type I was used here as a model of a pre-intravasation microenvironment through which, in vivo, tumor cells move to form metastases (15). In addition, due to its long lifespan, this key ECM protein represents a preferential target for non-enzymatic post-translational modifications. The impact of these metabolic events 
on tumor cell proliferation and migration was determined for optimal levels of carbamylation and glycation of collagen type I. For this, carbamylation was investigated by analyzing the electrophoretic mobility of $\alpha_{1}, \alpha_{2}$ collagen chains and by quantifying homocitrulline residues using HPLC. Glycation was only assessed by AGE spectrofluorimetric measurements. Although the samples were under denatured conditions, it was impossible to detect by electrophoresis the $\alpha_{1}$ and $\alpha_{2}$ chains of glycated collagen (data not shown): probably due to the presence of crosslinks which prevented the migration of proteins inside the polyacrylamide gel.

Using time-lapse videomicroscopy, we demonstrated that carbamylated collagen, moderately but significantly inhibited individual HT1080 cell speed by $12 \%$ compared to its native form. To our knowledge, these data are the first to demonstrate that carbamylated collagen reduces tumor cell migration. This is in agreement with clinical studies showing that ESRD-induced RCC in dialyzed patients is less metastatic than sporadic RCC $(16,17)$. Indeed, the presence of carbamylated proteins has been detected in mesangial cells and in ECM renal biospsies of dialyzed ESRD patients $(12,18)$. By contrast, glycated collagen inhibited cell migration considerably more than the carbamylated one by decreasing individual cell speed by $47 \%$. This differential effect was confirmed using other cancer cell lines specially skin SK-MEL-28 and mammary MDA-MB-231 cells (data not shown). Using bulk methods such as transwell migration assay, it was reported that ribose-induced glycation of collagen also affected, but to a lesser extent, the migration of $\mathrm{H} 322$ lung carcinoma cells and Panc-1 pancreatic carcinoma cells, respectively, by $16-20 \%$ (19). Altogether, the above data and those obtained with other glycation modes such as glycolaldehyde (20) and 3-deoxyglucosone (21) or with aged collagen originated from old rats (19), strongly suggest that glycation reduces the in vitro invasive migration of tumor cells. However, the extent of this inhibition depends on the type of the studied tumor cell line.

It is well known that the cell migration cycle, on coatedECM proteins basically depends on the adhesion process and requires a dynamic continuum formation and disassembly of the adhesion complexes and actin cytoskeleton (22). Concerning cell adhesion, we demonstrated that glycation dramatically delayed this process whereas carbamylation did not. Indeed, cell adhesion was strongly reduced at early stages after seeding on glycated collagen. Most of the cells adhered after only $4 \mathrm{~h}$ of incubation, whereas with native or carbamylated collagens all the cells adhered between $30 \mathrm{~min}$ and $1 \mathrm{~h}$. Contrarily to our findings, it has been reported that methylglyoxal-glycated collagen irreversibly impaired HT1080 cell adhesion (23). These contrasting data highlight that the cell adhesion process depends on the glycation mode.

The ability of glycated collagen to delay tumor cell adhesion and to decrease cell movement suggests that this modified matrix protein affects the formation of focal adhesions. These signaling complexes include critical adaptor proteins such as vinculin as well as kinases such as FAK that are especially involved in the signal transmission from the ECM to the cell cytoskeleton. Vinculin is described as an actin binding protein that is recruited to the $\beta$ integrin cytoplasmic tail via its interaction with talin (24). Upon activation by integrins, the tyrosine kinase FAK undergoes autophosphorylation $\left(\mathrm{Tyr}^{397}\right)$ and forms a complex with Src and other cellular proteins to trigger downstream signaling through kinase activity or scaffolding function $(25,26)$. Consequently, both proteins are representative as critical regulators of integrin-mediated adhesion and migration. In the present study we showed that the distribution of vinculin patches localized throughout the whole cell body on native collagen, are less present on glycated form and move to the cell periphery. This dramatic perturbation of vinculin distribution may explain the disorganization of actin cytoskeleton and loss of stress fibers. In addition, our results revealed that the level of FAK expression and phosphorylation was markedly inhibited compared to native collagen. It should be noted that with carbamylated collagen, actin organization and vinculin distribution were not affected (data not shown), whereas a moderate inhibition of FAK phosphorylation was observed. Recently, the decrease of FAK phosphorylation has been described for retinal microvascular endothelial cells incubated with methylglyoxal-modified fibronectin (27) or for keratinocytes incubated with glycoaldehyde-modified bovine serum albumin which correlated for those cells to a loss of their migratory and proliferation abilities (28).

Mechanistically, upstream events leading to impaired adhesion and migration consecutive to ribose-glycation could occur during the recognition phase between $\beta_{1}$ integrin, highly expressed on HT1080 cells (29) and RGD ligands existing on the collagen chains. Indeed, this is supported by the fact that for rat $\alpha_{1}$ collagen chain, ribose-glycation takes place on lysine residues within preferential AKG and PKG motifs (30) which we identified to be located nearby RGD sequences. This location was deduced by examining the peptide map presented in Fig. 8. Such modifications could alter the triple helical structure of collagen leading to changes in cell-matrix interactions. This is supported by IR microspectroscopic studies of glycated collagen fibers revealing marked conformational changes at the level of their secondary structure (unpublished data). On the other hand, the deleterious impact of glycation of arginine residues upon cell-matrix interactions cannot be totally excluded. Indeed, using methylglyoxal as glycating agent, it has been demonstrated that arginine within the RGD collagen binding sites, preferentially reacts with this compound and consequently affect HT1080 cell adhesion and spreading (23). Concerning carbamylation, its minor impact on tumor cell migration is in agreement with the capacity of this modified collagen to retain its triple helical structure as recently demonstrated by our laboratory using Raman microspectroscopy (31).

In conclusion, our data indicate that collagen glycation and carbamylation differentially affect in vitro tumor cell migration. Consequently, our study suggests that such posttranslational modifications of the matrix proteins need to be taken into account when designing in vitro experiments to understand cell-matrix interaction mechanisms or to develop anti-metastatic drugs.

\section{Acknowledgements}

This study was supported by grants of Institut National du Cancer (INCa), Cancéropôle Grand-Est and FEDER/CPER Champagne-Ardenne. G.S. is a recipient for a doctoral fellowship from Cancéropôle Grand-Est and M.G. from Région 
Champagne-Ardenne. We thank Sylvie Ricord for linguistic assistance.

\section{References}

1. Jaisson S and Gillery P: Evaluation of non-enzymatic posttranslational modification-derived products as biomarkers of molecular aging of proteins. Clin Chem 56: 1401-1412, 2010.

2. Kraus LM and Kraus AP: Carbamoylation of amino acids and proteins in uremia. Kidney Int 78: 102-107, 2001.

3. Baynes JW and Thorpe SR: Glycoxidation and lipoxidation in atherogenesis. Free Radic Biol Med 28: 1708-1716, 2000.

4. Monnier VM: Intervention against the Maillard reaction in vivo. Arch Biochem Biophys 419: 1-15, 2003.

5. Hora M, Hes O, Reischig T, Urge T, Klecka J, Ferda J, Michal M and Eret V: Tumors in end-stage kidneys. Transplant Proc 40: 3354-3358, 2008.

6. Paul RG and Bailey AJ: Glycation of collagen: the basis of its central role in the late complications of ageing and diabetes. Int J Biochem 28: 1297-1310, 1996.

7. Jemal A, Siegel R, Ward E, Murray T, Smigal C and Thun MJ: Cancer statistics. CA Cancer J Clin 56: 106-130, 2006.

8. Ershler WB, Socinski MA and Greene CJ: Bronchogenic cancer, metastases, and aging. J Am Geriatr Soc 31: 673-676, 1983.

9. Ansari NA and Rasheed Z: Non-enzymatic glycation of proteins: from diabetes to cancer. Biomed Khim 3: 335-342, 2009 (In Russian)

10. Verzijl N, DeGroot J, Thorpe SR, Bank RA, Shaw JN, Lyons TJ, Bijlsma JW, Lafeber FP, Baynes JW and Tekoppele JM: Effect of collagen turnover on the accumulation of advanced glycation end products. J Biol Chem 275: 39027-39031, 2000.

11. Dyer DG, Dunn JA, Bailie KE, Lyons TJ, McCance DR and Baynes JW: Accumulation of Maillard reaction products in skin collagen in diabetes and aging. J Clin Invest 91: 2463-2469, 1993.

12. Kraus LM, Gaber L, Handorf CR, Marti HP and Kraus AP: Carbamoylation of glomerular and tubular proteins in patients with kidney failure: a potential mechanism of ongoing renal damage. Swiss Med Wkly 131: 139-145, 2001.

13. Garnotel R, Rittie L, Poitevin S, Monboisse JC, Nguyen P, Potron G, Maquart FX, Randoux A and Gillery P: Human blood monocytes interact with type I collagen through $\alpha_{x} \beta_{2}$ integrin (CD11 c-CD18, gp150-95). J Immunol 164: 5928-5934, 2000.

14. Millerot-Serrurot E, Guilbert M, Fourré N, Witkowski W, Said G Van Gulick L, Garnotel R and Jeannesson P: 3D collagen type I matrix inhibits the antimigratory effect of doxorubicin. Cancer Cell Int 13: 10-26, 2010.

15. Serebriiskii I, Castello-Cros R, Lamb A, Golemics EA and Cukierman E: Fibroblast-derived 3D matrix differentially regulates the growth and drug-responsiveness of human cancer cells. Matrix Biol 27: 573-585, 2008.

16. Satoh S, Tsuchiya N, Habuchi T, Ishiyama T, Seimo K and Kato T: Renal cell and transitional cell carcinoma in a japanese population undergoing maintenance dialysis. J Urol 174: 1749-1753, 2005 .
17. Kojima Y, Takahara S, Miyake O, Nonomura N, Morimoto A and Mori H: Renal cell carcinoma in dialysis patients: a single center experience. Int J Urol 13: 1045-1048, 2006.

18. Kraus LM, Jones MR and Kraus AP: Essential carbamoyl-amino acids formed in vivo in patients with end-stage renal disease managed by continuous ambulatory peritoneal dialysis: isolation, identification and quantification. J Lab Clin Med 131: 425-431, 1998.

19. Bartling B, Desole M, Rohrback S, Silber R and Simm A: Age-associated changes of extracellular matrix collagen impair lung cancer cell migration. FASEB J 23: 1510-1520, 2009.

20. Morita K, Urabe K, Moroi Y, Koga T, Nagai R, Horiuchi S and Furue M: Migration of keratinocytes is impaired on glycated collagen I. Wound Repair Regen 13: 93-101, 2005.

21. Loughlin DT and Artlett CM: Modification of collagen by 3-deoxyglucosone alters wound repair healing through differential regulation of p38 MAP kinase. PLoS One 6: e18676, 2011.

22. Parsons JT, Horwitz AR and Schwartz MA: Cell adhesion: integrating cytoskeletal dynamics and cellular tension. Nat Rev Mol Cell Biol 11: 633-643, 2010

23. Paul RG and Bailey AJ: The effect of advanced glycation endproduct formation upon cell-matrix interactions. Int $\mathrm{J}$ Biochem Cell Biol 31: 653-660, 1999.

24. Humphries JD, Wang P, Streuli C, Geiger B and Humphries MJ: Vinculin controls focal adhesion formation by direct interactions with talin and actin. J Cell Biol 179: 1043-1057, 2007.

25. Zhao J and Guan JL: Signal transduction by focal adhesion kinase in cancer. Cancer Metastasis Rev 28: 35-49, 2009.

26. Worth D and Parsons M: Advances in imaging cell-matrix adhesions. J Cell Sci 123: 3629-3638, 2010.

27. McDonald DM, Coleman G, Bhatwadekar A, Gardiner TA and Stitt AW: Advanced glycation of the Arg-Gly-Asp (RGD) tripeptide motif modulates retinal microvascular endothelial cell dysfunction. Mol Vis 15: 1509-1520, 2009.

28. Zhu P, Yang C, Chen LH, Ren M, Lao G and Yan L: Impairment of human keratinocyte mobility and proliferation by advanced glycation end products-modified BSA. Arch Dermatol Res 303: 339-350, 2011.

29. Grenz H, Caronetta $S$ and Goodman $S: \alpha_{3} \beta_{1}$ integrin is moved into focal contacts in kidney mesangial cells. J Cell Sci 105: 739-751, 1993.

30. Mikulikova K, Eckhardt A, Pataridis S and Miksik I: Study of posttranslational non-enzymatic modifications of collagen using capillary electrophoresis/mass spectrometry and high performance liquid chromatography/mass spectrometry. J Chromatogr A 1155: 125-133, 2007.

31. Jaisson S, Lorimier S, Ricard-Blum S, Sockalingum GD, Delevallée-Forte C, Kegelaer G, Manfait M, Garnotel R and Gillery P: Impact of carbamylation on type I collagen conformational structure and its ability to activate human polymorphonuclear neutrophils. Chem Biol 13: 149-159, 2006. 